\title{
Variabilidade espacial físico-química de materiais superficiais sob uma vertente de Cerrado em estágio de recuperação
}

\section{Variabilidade espacial físico-química de materiais superficiais sob uma vertente de Cerrado em estágio de recuperação}

Fabiana Cristina dos Santos

Mestranda em Geografia pela

Universidade Federal de Uberlândia/MG - Brasil

fabianaqgufu@gmail.com

Sílvio Carlos Rodrigues

Prof. Dr. do IG/PPGEO da Universidade Federal de Uberlândia/MG - Brasil

$\underline{\text { silgel@ufu.br }}$

\begin{abstract}
Resumo
A distribuição dos materiais superficiais nas vertentes do ambiente de Cerrado em estágio de recuperação apresenta particularidades intrínsecas, que são relacionadas com o posicionamento topográfico, bem como com o formato e escoamento superficial da água. Todos estes aspectos também estão relacionados com a sazonalidade climática, típica deste ambiente. Os atributos físicos e químicos dos materiais superficiais relacionam-se fortemente com as características geomorfológicas, influenciadas em sua variabilidade espacial, exercendo papel preponderante na qualidade destes ecossistemas. Portanto, para o presente trabalho, foram feitas análises físicas de densidade aparente, porosidade total, textura e análises químicas dos elementos cálcio e potássio. Dessa forma, a caracterização da vertente através dos atributos físico-químicos, permitiu refletir a relação materiais superficiais-paisagem em uma área de Cerrado em estágio de recuperação.
\end{abstract}

Palavras-chave: Atributos do solo, vertentes, cerrado Brasileiro

\begin{abstract}
The distribution of surface materials in slopes of the Cerrado in recovery stage presents intrinsic particularities, which are related to the topographic positioning, as well as with the format and surface water flow. All these aspects are also pertinent to the climatic seasonality, typical of this environment. Physical and chemical attributes of surface materials relate strongly with the geomorphological characteristics, influenced in their spatial variability, playing an important role in the quality of these ecosystems. Thus, for this work, it was performed physical analyses of apparent density, total porosity, texture and chemical analyses of the elements calcium and potassium. Therefore, the characterization of the slopes through the physicochemical attributes allowed to reflect the relationship between surface materials and landscape in a Cerrado area in recovery stage.
\end{abstract}

Keyword: soil attributes, slopes, Brazilian Savanna 


\section{INTRODUÇÃO}

Materiais superficiais são constituídos de camadas ou horizontes de compostos minerais e/ou orgânicos, com diferentes espessuras, que constituem o denominado perfil de intemperismo. De acordo com Ab’Sáber (1969), a estrutura superficial, são detritos superficiais ligados a determinadas formas de transportes, em condições morfogenéticas específicas. É também denominada de depósito de cobertura elaborado por agentes morfogenéticos sob uma determinada condição climática, presente nos diferentes compartimentos topográficos.

Estes materiais inconsolidados, estão constantemente em atividade química, onde inúmeras reações se processam ao mesmo tempo dentro de cada uma de suas fases (sólida, líquida e gasosa), entre elas e delas com o ambiente. Devido a sua alta reatividade, a maioria dos fenômenos químicos ocorrem nas partículas menores do solo, chamada fração coloidal.

De acordo com Ronquim (2010) as argilas minerais, as substâncias húmicas e os óxidos de ferro e alumínio possuem determinada superfície de troca e são os principais coloides responsáveis pela capacidade de troca de cátions (CTC) sob condições tropicais. Em razão do maior número de cargas negativas do que positivas desses coloides, a adsorção é principalmente de cátions. No entanto, há alguns sítios nestes coloides com cargas positivas que podem atrair ânions (principalmente nos óxidos de ferro e alumínio).

Em relação aos atributos físicos, a densidade aparente tem sido usada principalmente como indicador da compactação, assim como para medir a porosidade total (REINERT et al., 2006).

Para a realização deste estudo foram amostradas, camadas superficiais em profundidades 0-5 cm, 5-10 cm e 10-30 cm, com objetivo de estudar a variabilidade espacial da densidade, porosidade e dos elementos cálcio e potássio dos materiais superficiais, empregando técnicas de geoestatística, determinando a dependência espacial por meio de semivariogramas e construindo mapas de isolinhas e superfícies com uso da técnica de interpolação por krigagem. A área de estudo está localizada na bacia hidrográfica do Rio Uberabinha, no Triângulo Mineiro, a fim de caracterizar a relação materiais superficiais-paisagem em uma vertente de Cerrado em estágio de Recuperação.

\section{2. ÁREA DE ESTUDO}

A área de estudo (Figura 1), em que as amostras serão coletadas, se localiza na Fazenda Experimental do Glória, inseridas no polígono cujas coordenadas em UTM são longitude 794137.81 E, latitude 7900048.55 S; longitude 794256.79 E, latitude 789898.79 S; longitude794254.32 E, latitude 7900019.93 S; longitude 794050.39 E, 7899977.63 S fuso 22, Datum WGS 84 a uma 
altitude entre 850 e 860 metros, presentes na bacia hidrográfica do Córrego do Glória, afluente da margem direita do Rio Uberabinha e subafluente do rio Araguari. Esta está no município de Uberlândia - MG sendo propriedade da Universidade Federal de Uberlândia.

De acordo com Alves (2007), as estações, chuvosa e seca, duram cerca de seis meses cada, devido ao deslocamento da área de influência das massas de ar que atuam sobre a região, que são elas: Massa Equatorial Continental, a Tropical Atlântica e a Massa de Ar Polar.

Segundo Ab'Saber (1977) o Domínio Morfoclimático do Cerrado é caracterizado por chapadões cobertos por vegetação de cerrado e penetrado por floresta-galeria ao longo dos cursos d'água. A vegetação da área de estudo é dividida em três tipos, ocorrendo cerrado senso restrito, onde predominam árvores baixas, inclinadas, tortuosas, com ramificações irregulares e retorcidas e presença de serapilheira.

Na parte inferior da vertente, ocorre uma fitofisionomia com a palmeira do Buriti (Mauritia Flexuosa) emergente, em meio a agrupamentos mais ou menos densos de espécies arbustivoherbáceas. Essas veredas de vertente são circundadas por Campo Limpo, geralmente úmido, e os buritis não formam dossel como ocorre no buritizal. No fundo do vale, acompanhando o canal fluvial, ocorre uma vegetação arbórea, latifoliada e adaptada às condições de alta umidade do solo.

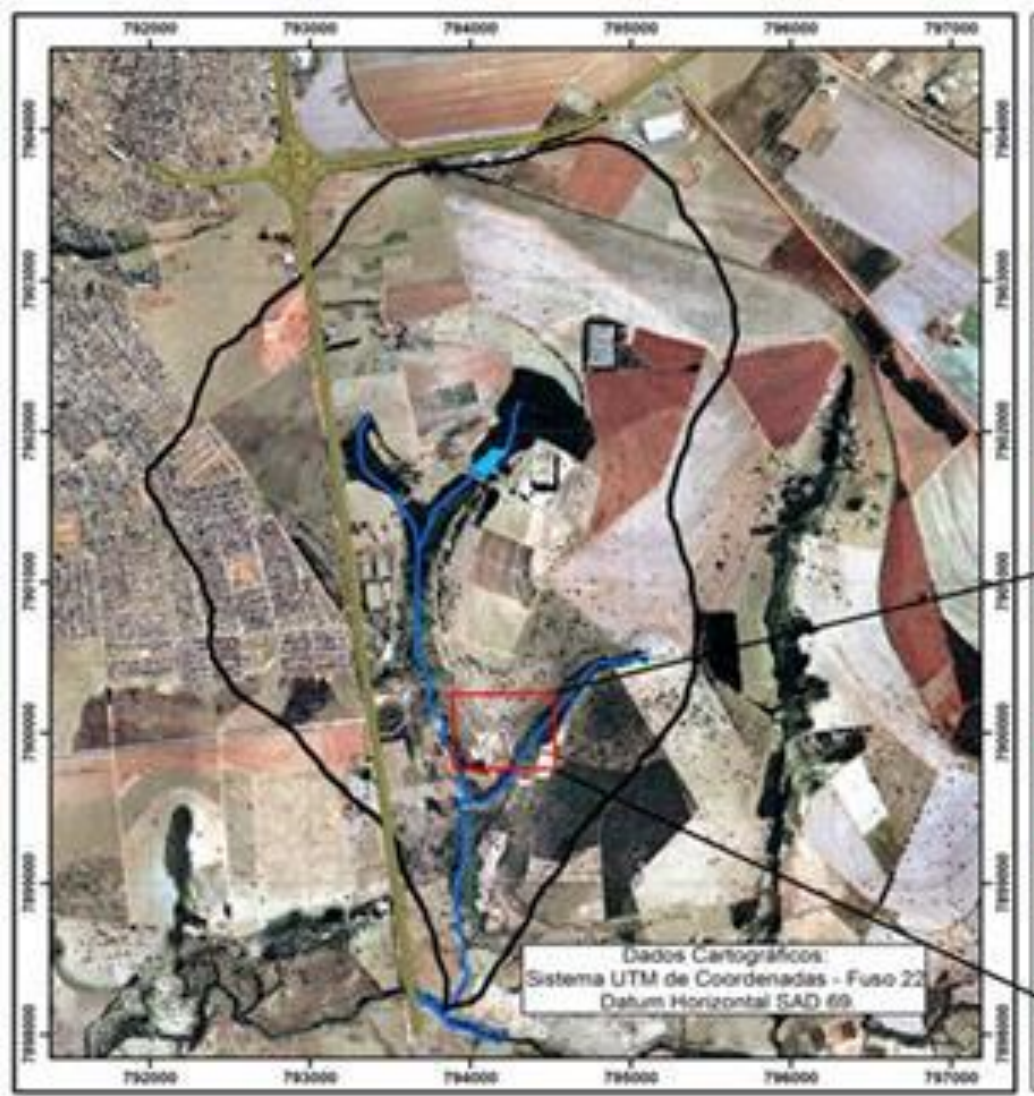

Figura 1: Área de Estudo Org. Barcelos, 2015.

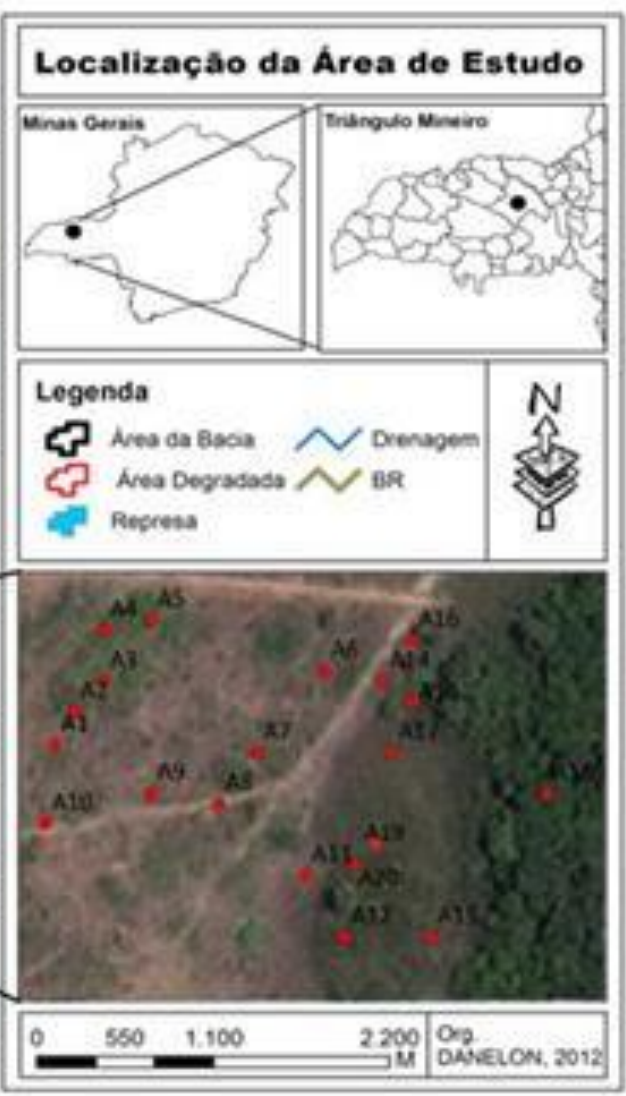

Localizaçâo da Area de Estudo

Legenda

Ares da Basas

Avea Degradads $\sim$ ba Regresa 


\section{MATERIAIS E MÉTODOS}

Para o desenvolvimento do presente trabalho foram feitas visitas à área de estudo, com o objetivo de coletar amostras de materiais superficiais, para avaliação das análises físicas de densidade aparente $(\mathrm{Da})$, textura $(\mathrm{T})$, porosidade total $(\mathrm{Pt})$ e químicas: cálcio $(\mathrm{Ca})$ e potássio $(\mathrm{K})$.

O layout de amostragem contou com coletas de amostras simples em 20 pontos em campo, por amostragem casualizada na vertente, sendo que a área foi dividida em quatro setores contendo cinco pontos cada, no sentido da alta para a baixa vertente, abarcando os 3 tipos de materiais superficiais encontrados nesta vertente.

Para determinação da (Da), foram coletadas 40 amostras indeformadas, nas profundidades de 0-5 e 5-10 cm, pelo método do anel volumétrico (100 $\left.\mathrm{cm}^{3}\right)$ (Embrapa 1997) (Figura 2). A porosidade total $(\mathrm{Pt})$, foi calculada através da relação existente entre densidade aparente (Da) e densidade de partícula (Dp), descrita no método da Embrapa (1997) e seu resultado é expresso em $\mathrm{kg} / \mathrm{mol}$.

Existindo a dependência ou correlação espacial entre a densidade, a porosidade e os elementos químicos, as estimativas para pontos não observados são obtidas pela técnica da krigagem.

Os valores pela krigagem, que consiste numa interpolação entre os pontos amostrados, foi efetuado pela ferramenta Krig, módulo Interpolação-Krigagem, do software ArcMap do pacote ArcGis versão 10.2.0.3348.

A textura foi avaliada retirando-se 40 amostras com trado holandês na profundidade de 0-10 e 10-30 cm, e analisada pelo método da pipeta, utilizando solução de $\mathrm{NaOH} 0,1 \mathrm{~mol} \mathrm{~L}^{-1}$ como dispersante químico e agitação mecânica em aparato de alta rotação ( 15.000 rpm) por 15 min, seguindo método proposto pela Embrapa (1997) e a interpretação de seus resultados, foram feitas através de um triângulo textural.

Para as análises químicas do elemento potássio(K), realizou-se extração por $\mathrm{HCl}$ 0,05 mol.L-1 + H2SO4 mol.L-1 analisado por colorimetria (Vettori 1969) e cálcio (Ca) extraído por KCl 1 mol.L-1 analisado por titulometria (Embrapa 1997).

As etapas desta pesquisa no intuito de atingir o objetivo proposto, podem ser visualizadas no fluxograma metodológico simplificado (Figura 2 ). 


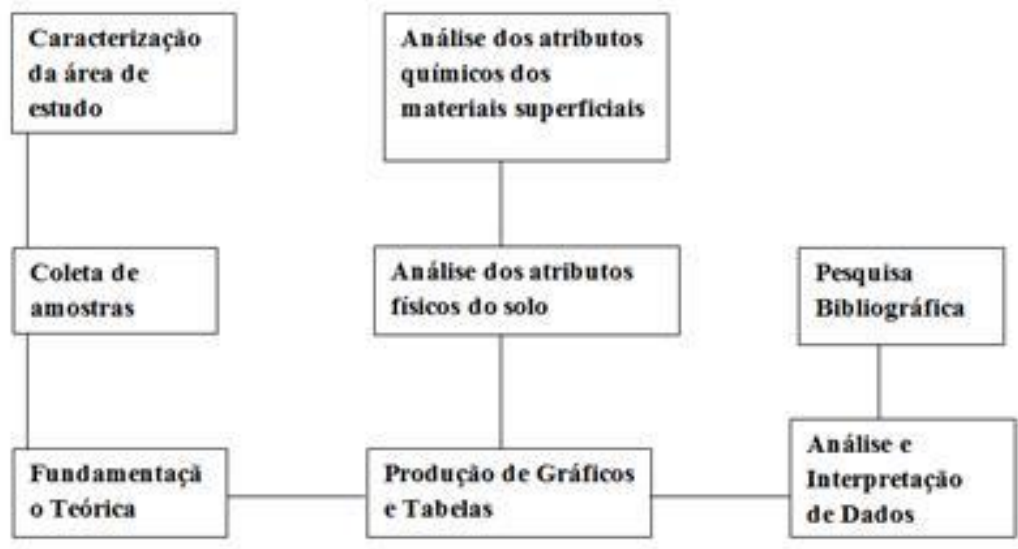

Figura 2:Fluxograma metodológico simplificado

Org. Santos, 2016.

\section{RESULTADOS}

Para as análises químicas, o cálcio (Ca)(Figura 3), apresentou valores de 2,0 mmolc.dm ${ }^{-3}$ para Latossolos e Gleissolos nas profundidades de 10 e $30 \mathrm{~cm} \mathrm{e} \mathrm{3,0} \mathrm{mmolc.} \mathrm{dm}^{-3}$ para Organossolos também nas profundidades 10 e $30 \mathrm{~cm}$. Esses resultados são considerados inferiores para fertilidade, nas diferentes classes amostrais, de acordo com os níveis ideais de nutrientes no solo segundo Boletim de Recomendação CFSEMG (1999). Porém trata-se de uma característica importante, pois essas concentrações são muito baixas em materiais superficiais ácidos nas regiões tropicais.

Para Ronquim (2010), significa que há pequenas quantidades de cátions, como $\mathrm{Ca}^{2+}$, saturando as cargas negativas dos coloides os quais são partículas de reduzido tamanho (entre $10^{-4} \mathrm{e}$ $10^{-7} \mathrm{~cm}$ ) e apresentam cargas superficiais que podem reter nutrientes (íons) de forma trocável.
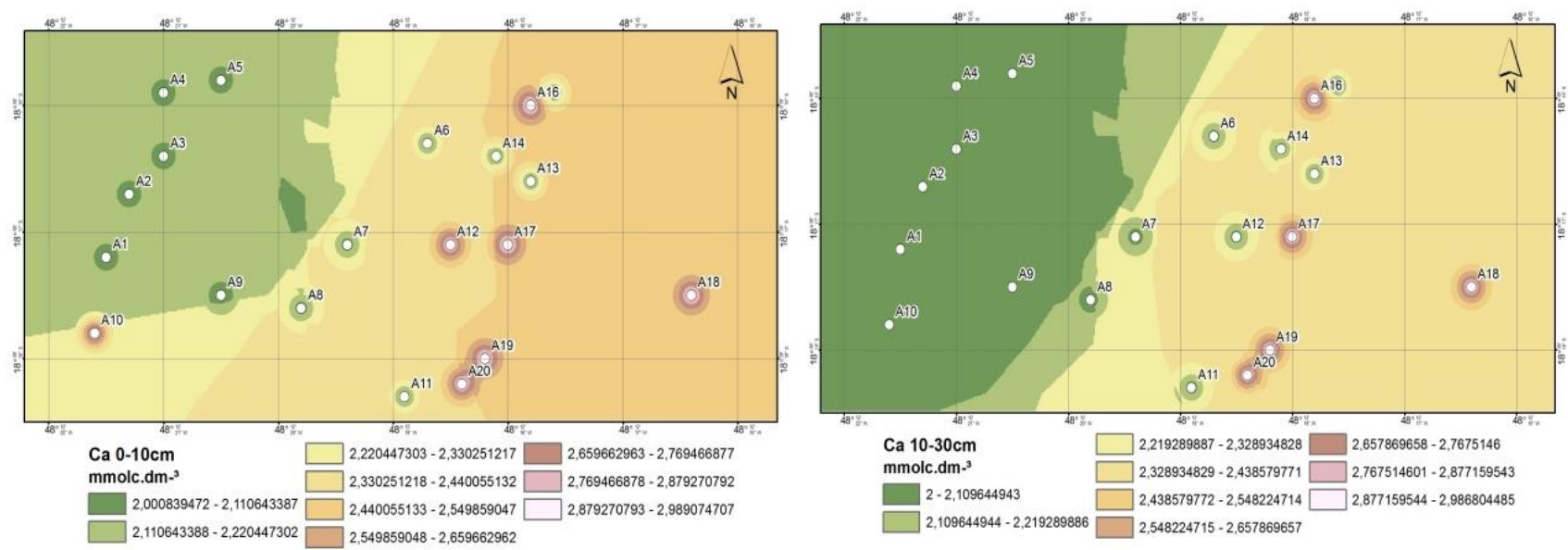

Figura 3: Elemento Cálcio (Ca) nas profundidades $0-10 \mathrm{~cm}$ e $10-30 \mathrm{~cm}$.

Org. Silva, 2016. 
O potássio (K) é absorvido pelas plantas na forma de íon $\left(\mathrm{K}^{+)}\right.$. As plantas absorvem-no da solução, cuja concentração é mantida pelo equilíbrio retido nos sítios trocáveis. Entretanto, quando a concentração na solução atinge valores muito baixos, pode haver difusão de parte do potássio contido nas estruturas dos argilo minerais e dissolução dos minerais primários que o contém, indicando que as formas de $\left(\mathrm{K}^{+}\right)$não trocáveis são potencialmente disponíveis para as plantas.

$\mathrm{Na}$ solução dos materiais superficiais (Figura 4), os valores encontrados para o Potássio, foram de 0,65 e 0,35 mmolc. $\mathrm{dm}^{-3}$ na profundidade 10 e $30 \mathrm{~cm}$ para os Latossolos; 0,5 e 0,2 mmolc. $\mathrm{dm}^{-3}$ na profundidade 10 e $30 \mathrm{~cm}$ nos Gleissolos e 0,6 e 0,3 mmolc. $\mathrm{dm}^{-3}$ profundidade 10 e $30 \mathrm{~cm}$ para Organossolos, também abaixo de acordo com o Boletim de Recomendação CFSEMG(1999).

Assim, nas diferentes classes amostrais pode-se observar que os valores, são maiores na profundidade de $10 \mathrm{~cm}$. Um fato talvez de maior relevância é que parte do potássio pode encontrarse imobilizada na cobertura de restos vegetais. Com a decomposição da matéria orgânica, esse potássio vai sendo liberado lentamente e mantendo, portanto, teores mais elevados em solução.
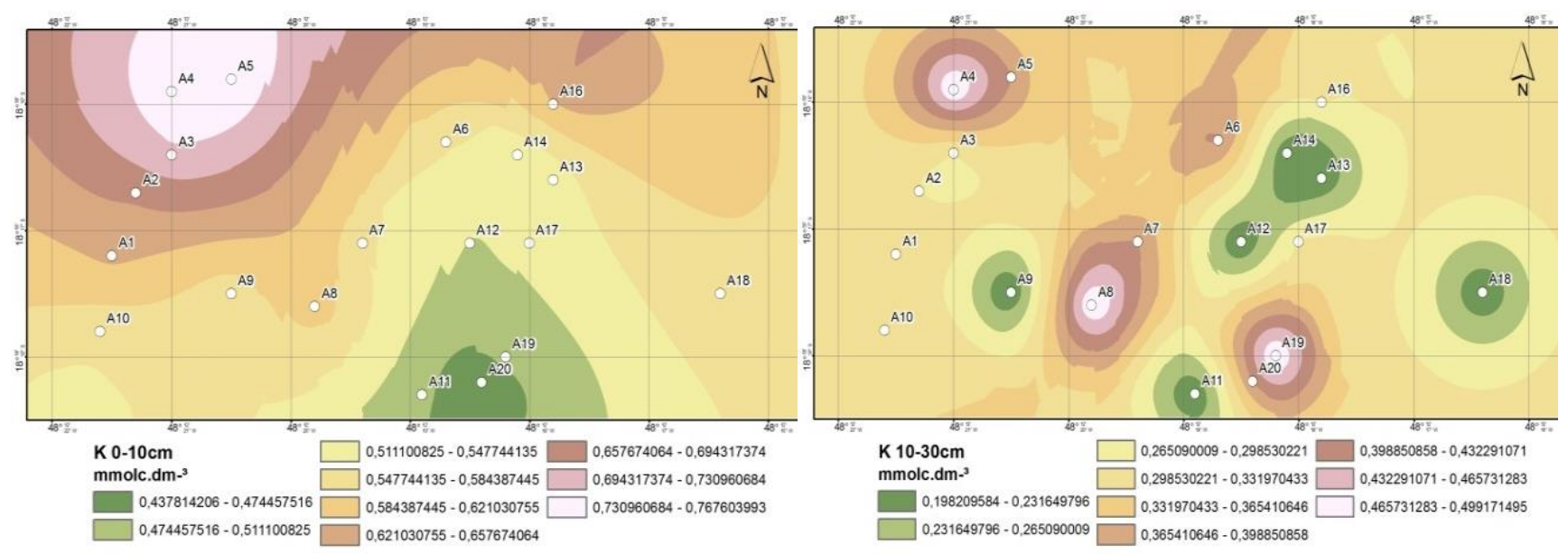

Figura4: Elemento Potássio (K), nas profundidades 0-10cm e 10-30cm.

Org. Silva, 2016.

A caracterização textural das camadas avaliadas encontra-se descrita no triângulo textural (Figura 5). Observa-se que na área de estudo ocorrem basicamente 3 tipologias de materiais superficiais, sendo predominante a textura arenosa, seguida por alguns pontos onde ocorre textura média. Estes materiais superficiais são compatíveis com o embasamento litológico da área, onde ocorrem predominantemente sedimentos areno-siltosos da Formação Marília. 


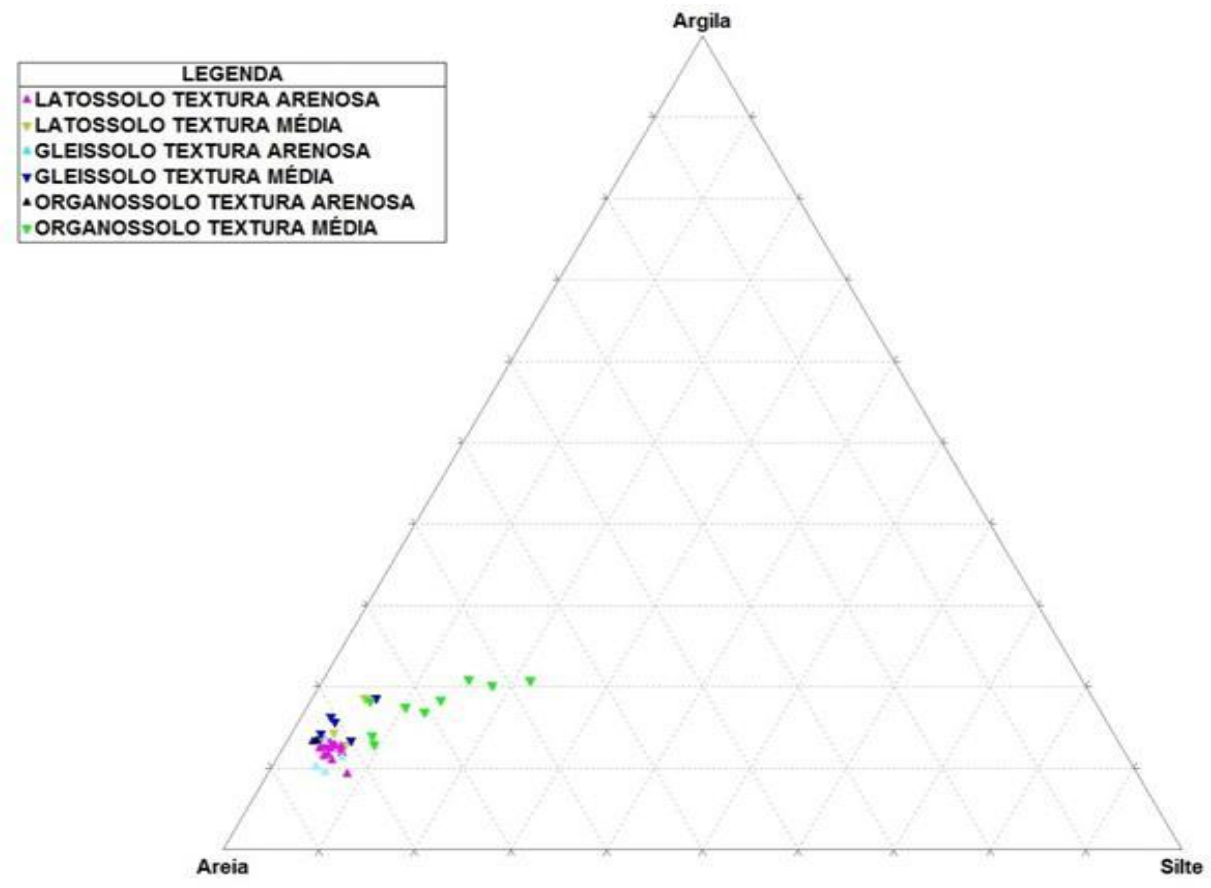

Figura 5: Classificação textural das amostras coletadas na área de estudo para análise.

Org. Barcelos, 2014.

Na Figura 6, verifica-se a disposição da densidade aparente, onde as pequenas áreas com ocorrência de concentrações de linhas de contorno fechadas indicam flutuações nos valores em intervalo de espaço amostral pequenos.
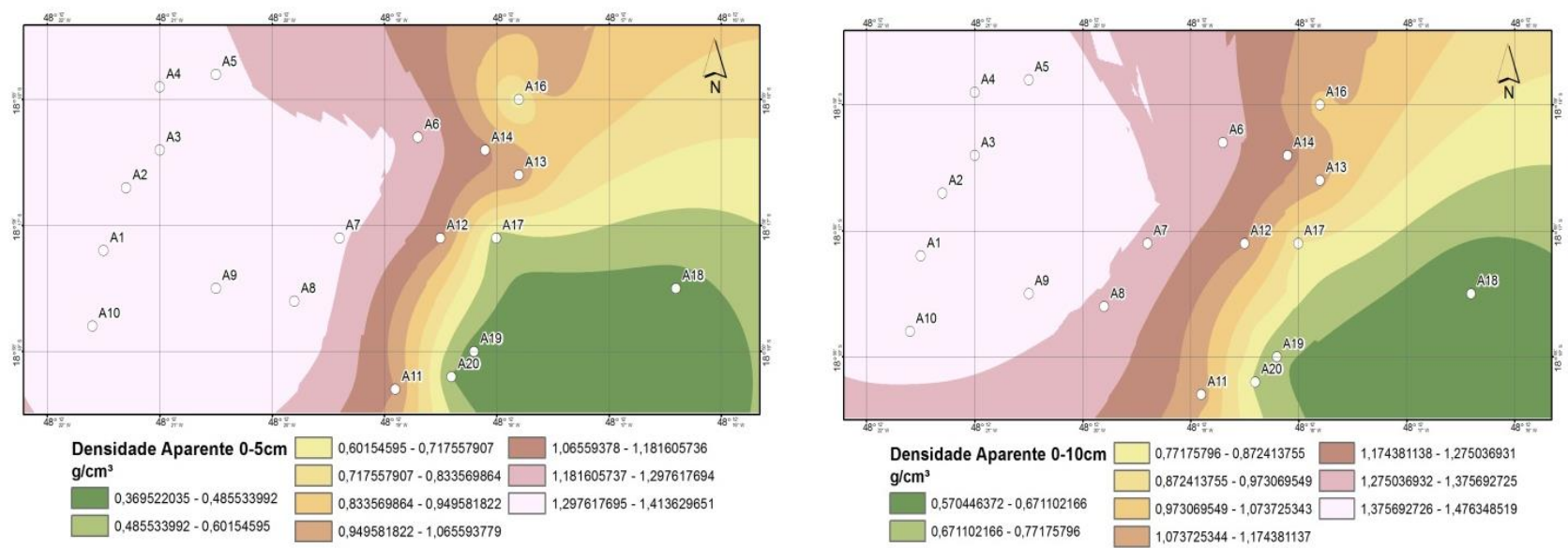

Figura 6: Densidade aparente nas profundidades de $0-5 \mathrm{~cm}$ e $5-10 \mathrm{~cm}$.

Org. Silva, 2016.

Valores críticos de Densidade Aparente para algumas classes texturais, propostos por Reinert e Reichert (2001) são de aproximadamente 1,30 a 1,40 kg. $\mathrm{dm}^{-3}$ para solos com horizonte de textura argilosa, de 1,40 a 1,50 kg.dm ${ }^{-3}$ para horizonte de textura franco - argilosa e de 1,70 a 1,80 $\mathrm{kg} \cdot \mathrm{dm}^{-3}$ para textura franco-arenosa, ou seja, para as condições texturais encontradas na unidade experimental deste trabalho, os valores de Densidade Aparente estão bem abaixo dos níveis críticos, 
uma vez que a análise trata-se da caracterização do Cerrado, cuja área, está em estágio de recuperação. As variações nos valores estão relacionadas ao tamanho e ao arranjo das partículas de areia e argila.

Há um aumento na Porosidade Total (Figura 7), quando relacionados às áreas de baixa vertente, no qual a Densidade Aparente é diminuída, concordando com as análises de Araujo, Goedert e Lacerda, (2007).

Os valores observados de Densidade Aparente e Porosidade Total para áreas de Cerrado em estágio de recuperação, são similares aos relatados em trabalhos também realizados nesse bioma, publicados por Fontenele (2006), Souza, Carneiro e Paulino (2005) e Silva et al. (2001). Este fato demonstra que as características topográficas que intercede na dinâmica hidrológica dos materiais superficiais, em função de mudanças de direção e agrupamento de fluxos interferem diretamente na estruturação física dos mesmos.
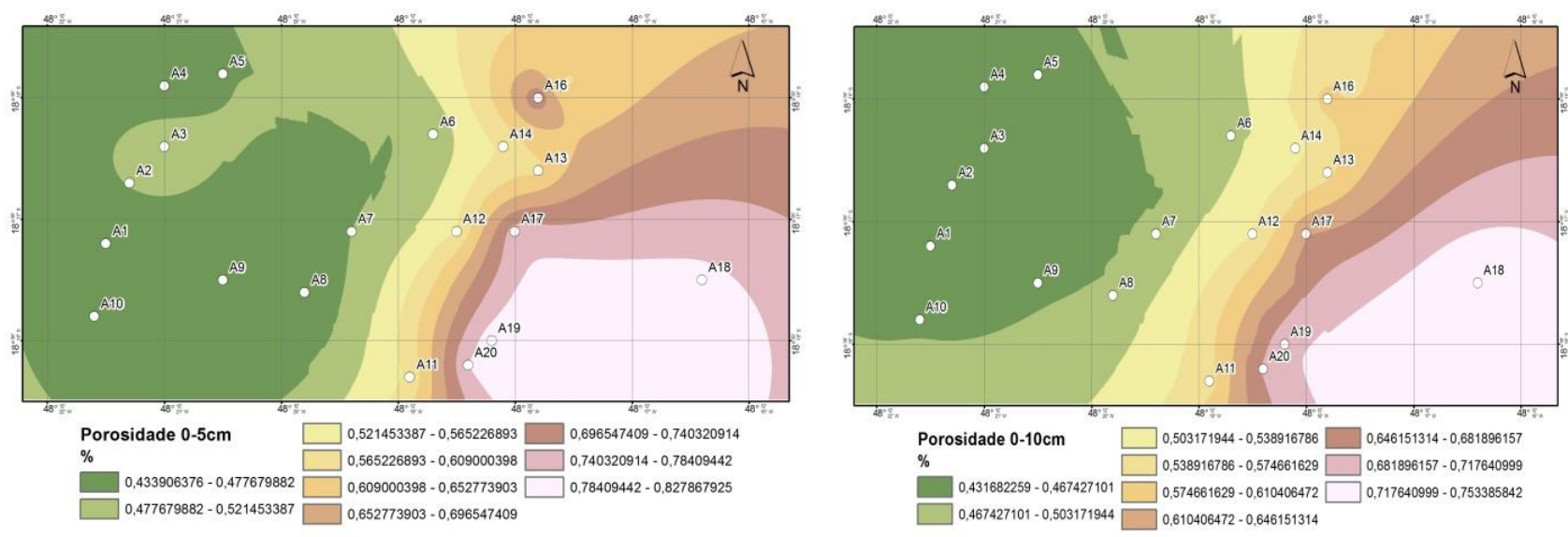

Figura 7: Porosidade total, nas profundidades $0-5 \mathrm{~cm}$ e $5-10 \mathrm{~cm}$.

Org: Silva, 2016.

Dessa forma, a baixa concentração dos elementos cálcio e potássio possuem relação estreita com os valores de densidade aparente e porosidade total, relatadas nesse estudo, uma vez que aredução da infiltração de água nos materiais superficiais contribui para um maior escoamento superficial e consequente, maior processo erosivo, lixiviando esses elementos químicos.

\section{CONSIDERAÇÕES}

Os valores de Porosidade Total demonstraram o mesmo padrão de diferenciação entre os Latossolos e Gleissolos em relação aos Organossolos, porém, valores maiores de Porosidade Total foram encontrados nos Organossolos, refletindo seu caráter menos denso e menos coeso. 
Neste sentido observa-se relação inversa entre os parâmetros de Densidade Aparente e a Porosidade Total. Esta associação, em menor escala, também tem relação com a textura destes materiais, que apesar de grande conteúdo de areia, possuem diferenciação em relação ao conteúdo de silte e argila, nos materiais de textura média.

Observa-se valores inferiores dos atributos químicos (cálcio $(\mathrm{Ca})$ e potássio $(\mathrm{K})$, de acordo com a classificação de fertilidade do boletim CFSEMG(1999), justificado pelas características de materiais superficiais, que sofrem lixiviação em climas tropicais.

\section{AGRADECIMENTOS}

O presente trabalho foi realizado com apoio do CNPq, Conselho Nacional de Desenvolvimento Científico e Tecnológico, Bolsista do CNPq/ Brasil CNPQ - PQ - 302654/2015-1 e Bolsa de PósGraduação em Mestrado CAPES.

\section{REFERÊNCIAS}

AB'SÁBER, A. N. Problemas do mapeamento geomorfológico no Brasil. Geomorfologia, São Paulo, v. 6, p. 1-16, 1969.

AB'SÁBER, A. N. Os domínios morfoclimáticos na América do Sul: primeira aproximação. Geomorfologia, São Paulo, v. 52, p. 1-22, 1977.

ALVARENGA, M.I.N.:DAVIDE, A.C. Características físicas e químicas de um Latossolo Vermelho-Escuro e a sustentabilidade de agrossistemas. Revista Brasileira de Ciência do Solo, Viçosa, v. 23, p.933-942, 1999.

ALVES, R. A. Monitoramento dos Processos Erosivos e da Dinâmica Hidrológica e de Sedimento de uma Voçoroca: estudo de caso na Fazenda do Glória na zona rural de Uberlândia- MG. 2007. 104 f. Dissertação (Mestrado em Geografia), Instituto de Geografia, Universidade Federal de Uberlândia,2007.

ARAÚJO, R.; GOEDERT, W.J.; LACERDA, M.P.C. Qualidade de um solo sob diferentes usos e sob cerrado nativo. Revista Brasileira de Ciência do Solo, Viçosa, v.31, p.1099-1108, 2007.

COMISSÃO DE FERTILIDADE DE SOLO DO ESTADO DE MINAS GERAIS (CFSEMG). Recomendações para o uso de corretivos e fertilizantes em Minas Gerais. 5 ed. Lavras: CFSEMG, 1999. 359p.

EMPRESA BRASILEIRA DE PESQUISA AGROPECUÁRIA. Centro Nacional de Pesquisa de Solos. Manual de métodos de análise de solo. 2. ed. Rio de Janeiro: Embrapa CNPS, 1997. 212 p.

FONTENELE, W. Indicadores Físicos e Hídricos da Qualidade de um Latossolo Amarelo Distrófico Sob Diferentes Sistemas De Manejo no Cerrado Do Piauí. 2006. 52. f. Dissertação (Mestrado em Agronomia) Centro de Ciências Agrárias, Universidade Federal do Piauí, Teresina, 2006 
REINERT, D. J.:REICHERT, J.M. Propriedades físicas de solos em sistema plantio direto irrigado. In :CARLESSO, R.; PETRY, M.; ROSA, G.: CERETTA, C.A. Irrigação por Aspersão no Rio Grande do Sul, Santa Maria, 2006. p. 114-131.

RONQUIM, C. C. Conceitos de fertilidade do solo e manejo adequado para as regiões tropicais. Boletim de Pesquisa e Desenvolvimento, v.8, Campinas, 2010. 26 p.

SILVA, V. R.: REINERT, D. J.:REICHERT, J.M. Densidade do solo, atributos químicos e sistema radicular do milho afetados pelo pastejo e manejo do solo. Revista Brasileira de Ciência do Solo, v.24, p.191-199, 2000a.

VETTORI, L. Métodos de análise de solo. Rio de Janeiro: Ministério da Agricultura, Equipe de Pedologia e Fertilidade do Solo, 1969. 24p.

Trabalho enviado em 28/04/2015

Trabalho aceito em 04/11/2016 